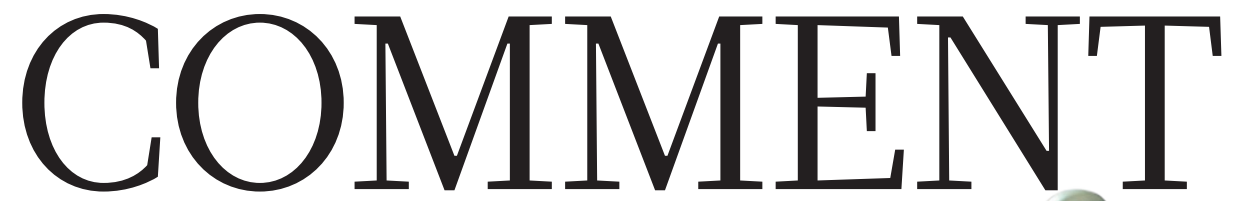

SPACE Did supermassive black holes drive the evolution of life itself? p.278
ART New York exhibition explores the surreal side of technology $\mathbf{p . 2 7 9}$
TECHNOLOgY Talking to a creator of therapeutic robots $\mathbf{p . 2 8 0}$
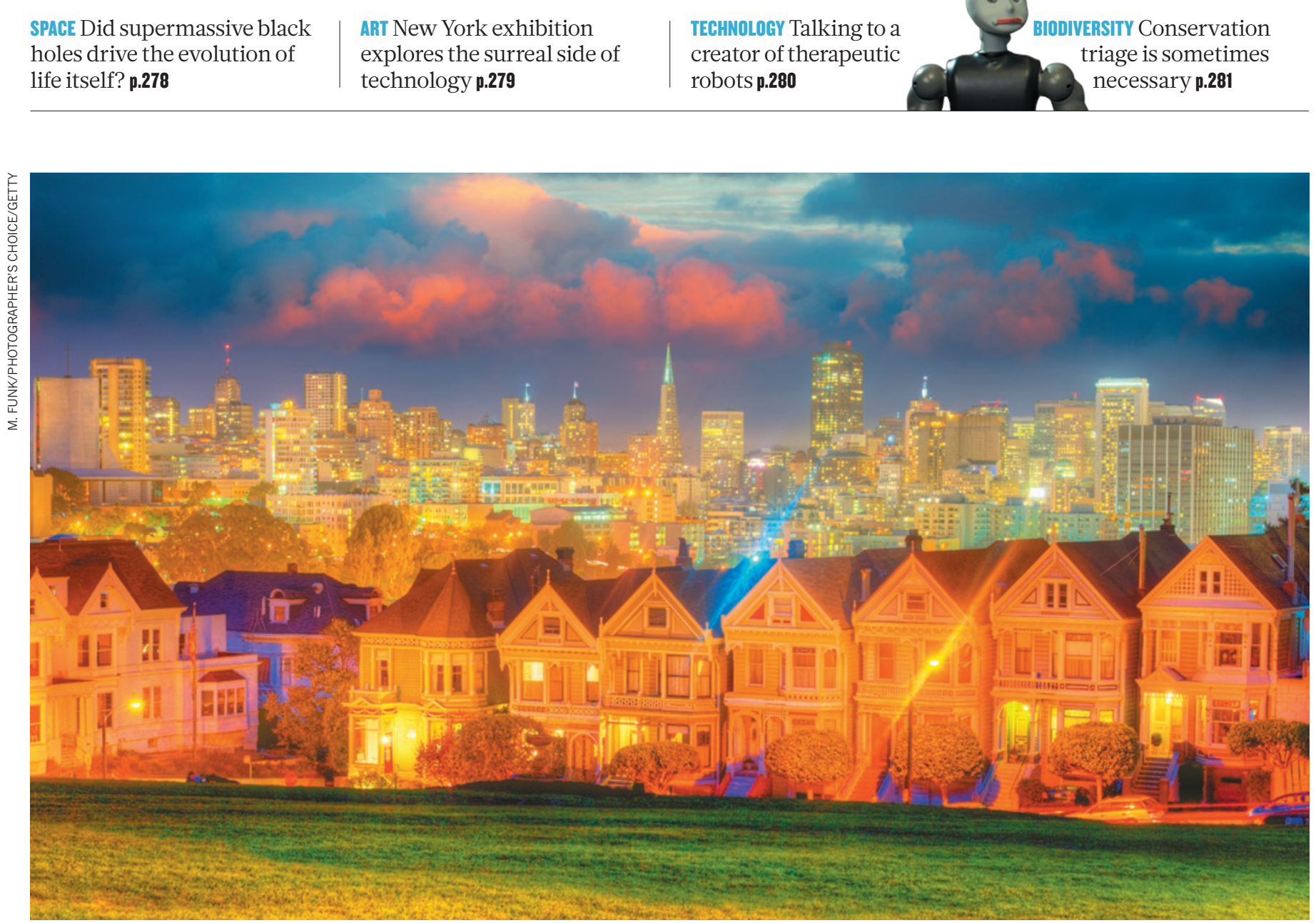

Uses such as lighting, heating and cooling in buildings account for almost $40 \%$ of the energy consumed in the United States.

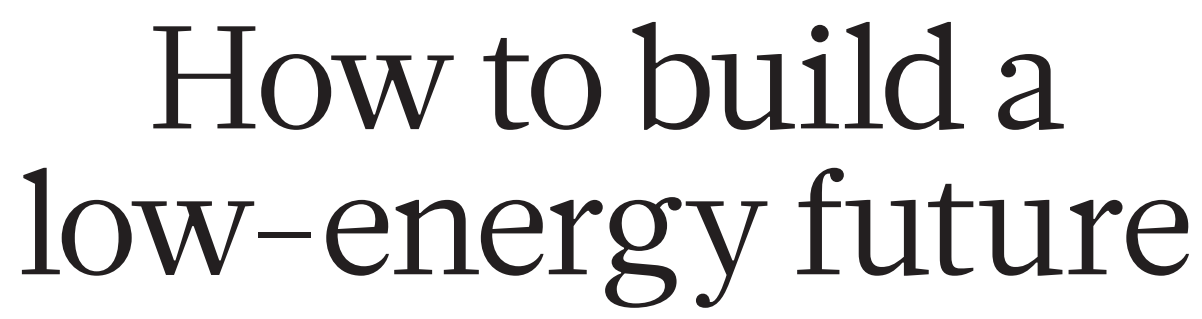

Advanced construction technologies promise huge energy savings, says Philip Farese. Investment is needed to bring them to market and to encourage their use.

I

n 2010, the United States used 98 quadrillion British thermal units (quads) cof energy - about $20 \%$ of the world's total - on everything from transport to entertainment. A surprisingly large amount - 40 quads - went into buildings for uses such as space heating, cooling, lighting and computing. Assuming that business continues as usual, by 2030, the nation will require 43 quads of energy for buildings each year ${ }^{1}$.
There is huge room for improvement without sacrificing an ounce of comfort. Much more should be invested in developing energy-saving technologies, in bringing them to market and in encouraging their use.

I, along with colleagues at the National Renewable Energy Laboratory (NREL) in Golden, Colorado, and at the US Department of Energy (DOE), have reviewed more than 300 publications and sought the advice of 65 experts to determine how much US energy demand for buildings might be cut. We find ${ }^{2}$ that cost-effective technologies available now could reduce energy use in buildings by up to $30 \%$ by 2030 , which is in line with others' findings ${ }^{3}$.

Add in the affordable emerging technologies that are expected to be available in the next 5 years or so, and the potential reduction reaches 55\%. Including all $>$ 


\section{GOING DOWN}

Energy demand in US buildings could be cut by up to $80 \%$ through investment and marketing.
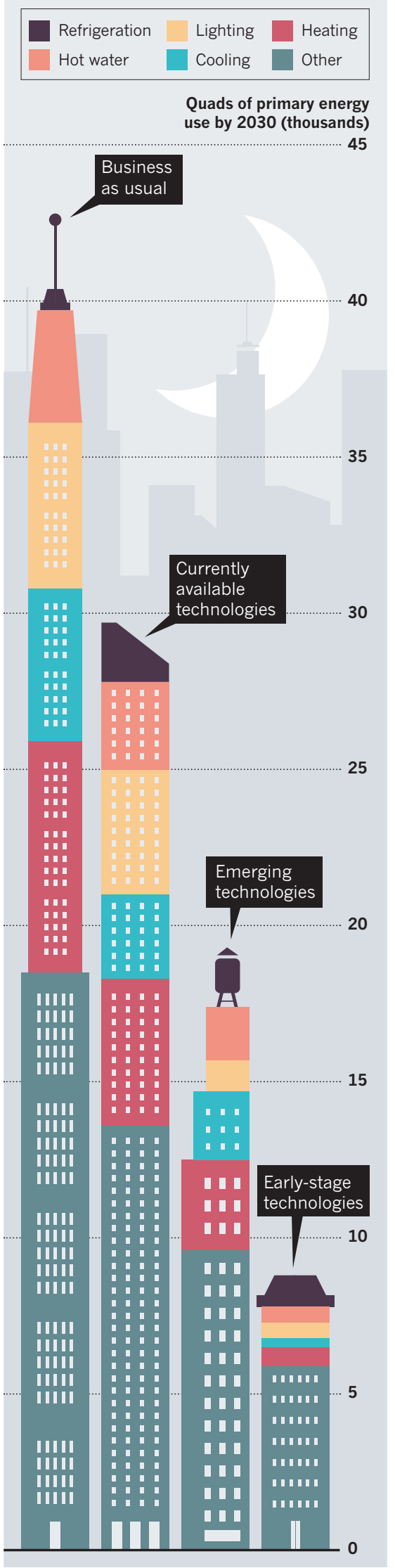

technologies that are in the early stages of research and development (R\&D) brings this cut in energy use to an astonishing $80 \%$ (see 'Going down').

Some researchers have pointed out that efficiency improvements can lead to an increase in demand ${ }^{4}$. Such 'rebound' effects are real, but are expected to soak up no more than $15 \%$ of energy savings ${ }^{5}$. Some people might heat their homes a bit more in the winter, but very few will wash more clothes or cook more meals. Other researchers argue ${ }^{4}$ that the money saved through energy efficiency will be spent by consumers on energy-intensive luxuries, such as longdistance flights. But consumers are likely to spend in line with their usual budget. For every dollar spent in the United States, about $8 \%$ goes back to energy costs, including the energy used to manufacture, sell and transport goods - an indirect rebound effect.

Even accounting for these effects, energy savings should still exceed $20 \%$ from currently available technologies and $45 \%$ from emerging technologies ${ }^{2}$. The $80 \%$ reduction as a result of advanced technologies becomes $65 \%$ when rebound effects are included, meaning that the projected 43 quads of demand could be met using some 14 quads of energy. The national energy bill could be reduced by as much as US $\$ 275$ billion a year ${ }^{2}$ if just a fraction of that amount was invested strategically.

According to my analysis, energy-use intensity - the amount of energy used per unit area of building space per person - actually rose in the United States by $10 \%$ from 1980 to 2010 . Because of this, some say that efficiency measures serve to increase energy use. But this rise results from an increase in demand for modern devices such as air-conditioning units and computers. Heating (of both water and space) and refrigeration have also seen a small rise in demand despite significant improvements in equipment efficiency - but by my calculation, their energy-use intensity has fallen by $43 \%$. Efficiency will need to be pursued aggressively in all areas, using approaches that range from increasing R\&D investment to maintaining appliance standards.

\section{HEAT AND LIGHT}

For centuries, most of the energy used to heat buildings came from burning fuels, which can provide no more than one unit of heat for each unit of energy. But many energyefficiency technologies are in the pipeline, and a few are particularly revolutionary.

Heat pumps could be much more efficient. They currently exchange at least three units of heat from inside and outside buildings per unit of electricity. When the thermodynamic effect of producing electricity is accounted for, the pumps become about as efficient as the best available gas furnaces. More than
11 million homes in southern and temperate climates in the United States already use them. Further savings could be made by improving the technologies used and by lowering the installation cost of pumps that extract heat from the ground. These can swap an impressive 8 units of heat for every unit of electricity. For water heating, we should encourage the adoption of electric and gas-fired pumps and solar heaters. Devices are now available that more than double the efficiency, at half the lifetime cost.

Meanwhile, liquid-desiccant technologies are starting to shift how people think about cooling and de-humidification. Current technology relies on the compression and expansion of vapour to drive heat out of a building. To remove moisture from the air, these often over-cool the air, then heat it up again. Solutions of brine, however, are much more efficient at extracting humidity. These systems use $30-50 \%$ less energy and are already commercially available from firms such as Advantix Systems in Sunrise, Florida, of which I am a vice-president. Systems that combine desiccant and evaporative cooling are on the horizon, and promise savings of $60-80 \%$.

For lighting, simply increasing the use of efficient technologies such as compact fluorescent bulbs could lessen the energy used by $35 \%$. The biggest opportunity lies with lightemitting diodes (LEDs), which could push energy use down by as much as $90 \%$. The DOE awarded Amsterdam-based electronics firm Philips \$10 million for producing an LED lamp that uses $85 \%$ less energy than an incandescent bulb, "Rebound" lasts roughly 25 times effects are are expected to soak up no more than $15 \%$ of energy savings." longer and provides the same quality of light. The bulb costs $\$ 50$, but saves the consumer \$200 in energy costs over its lifetime, compared with incandescent bulbs. The high purchase price is a sticking point, but manufacturers and the DOE plan to get the cost down to just $\$ 5$ in the next $5-10$ years.

Simple improvements to building insulation can also make a difference. For example, highly insulating windows currently cost about $\$ 1,000$ more than standard windows for a typical home, with that difference earned back through energy savings in 5-10 years. But the profit differential isn't large enough for distributors to justify the time needed to convince customers to buy the product. One solution could be to create web tools or mobile apps that easily showcase the advantages of efficient products.

Savings of up to $20 \%$ or more are available through changes to maintenance and operations procedures. For example, 'learning thermostats' in homes assess the daily schedule and adjust the temperatures of 


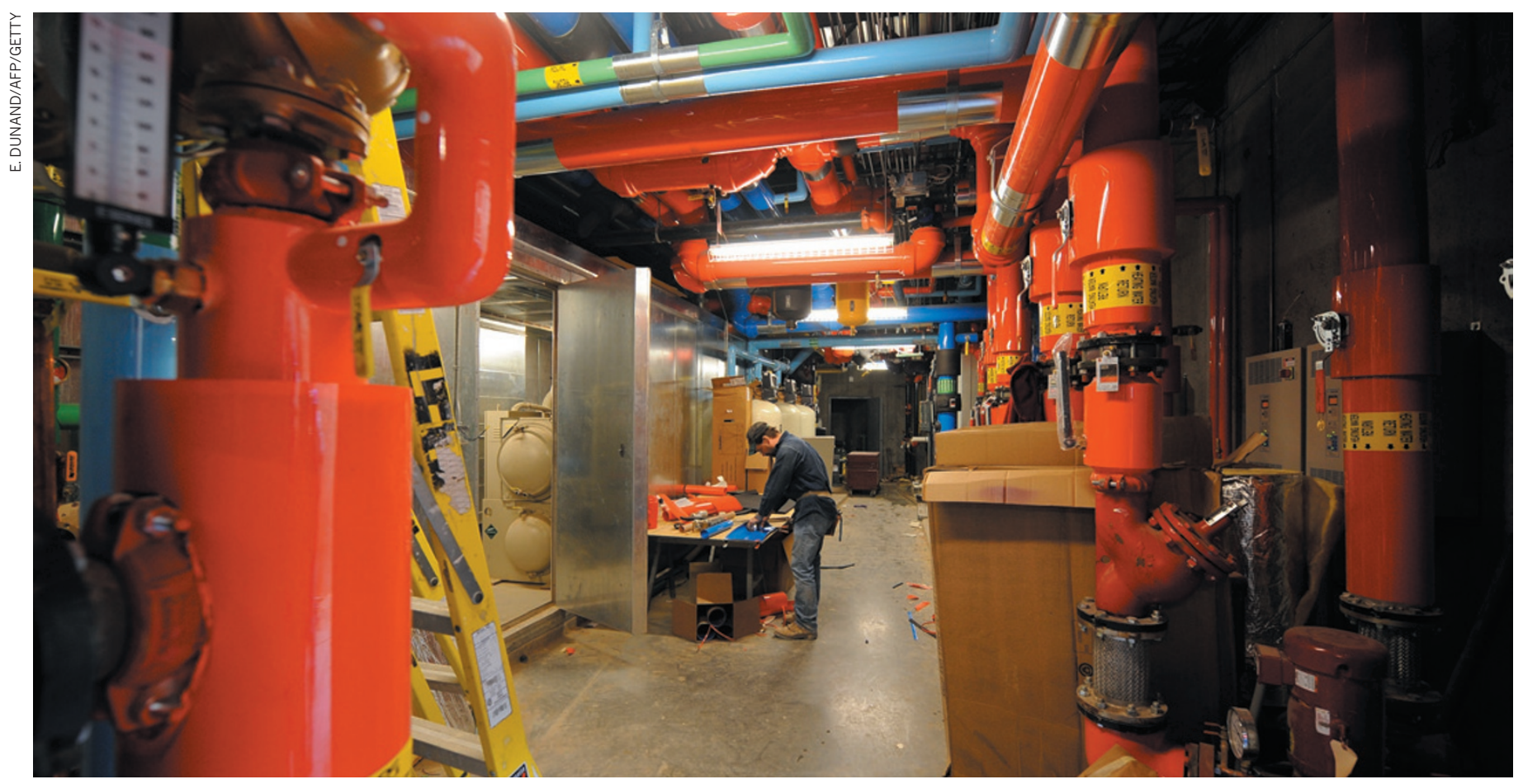

A heating and cooling system based on geothermal energy at a hospital in Greensburg, Kansas.

the rooms accordingly, and 'tune ups' on commercial buildings improve how they are run. Cars use control systems that are much more intelligent than those in our buildings.

\section{INVEST TO SAVE}

The barriers to $80 \%$ energy savings in buildings are well known. Consumers find it hard to evaluate the risks and benefits of technologies; investors may not benefit directly (why would a landlord invest in LED bulbs when tenants pay their own electricity bills?); and few of the latest technologies have been taken up by vendors. These small problems add up to big obstacles. But there are solutions.

Energy standards for US appliances were put in place between 1987 and 2010, for example, leading to savings of 3 quads in 2010. These are forecast to save a staggering 158 quads by 2070 (ref. 6). The DOE's Appliance and Equipment Standards programme is required by law to update appliance standards, but that takes effort. The most recent refrigerator standards, released in 2011, were developed after years of work, culminating in a 1,000-page report. Despite offering a return on investment of about a thousand to one, the rate of issuing standards has waxed and waned over time, and the programme has not always received the funding it needs. It is now on track, but no one knows for how long.

Building codes that were put in place in the 1970s have reduced energy use in newly constructed buildings by $30-40 \%$, leading to a saving of 0.45 quads per year ${ }^{7}$. Codes developed in 2010 will soon be in place that should save an extra 1.25 quads per year by 2030 - a huge improvement - and others in development could double those savings ${ }^{7}$. However, every state will need to adopt these codes individually, and many will need help with compliance.

Labels can be powerful, too. Since the DOE and the US Environmental Protection Agency introduced the ENERGY STAR programme in 1992 to test and label the efficiency of household equipment, energy use has fallen by about 1.6 quads per year ${ }^{8}$. Like appliance standards, this programme needs to be updated regularly. As new products raise the bar, old products need to lose their status. A recently introduced 'most efficient' ENERGY STAR label is a step in the right direction.

Further investment in R\&D could make a difference. A 2001 analysis $^{9}$ of selected DOEfunded research projects showed net energy cost savings of around $\$ 30$ billion from an investment of about $\$ 0.4$ billion in energyefficiency R\&D: a return of 75 to 1 .

Despite such rewards, the energy sector is hugely underfunded. Total R\&D investments from US public and private sources come to just $0.4 \%$ of the amount spent on energy bills (about $\$ 1.5$ billion per year in buildingsrelated $\mathrm{R} \& \mathrm{D})$. This percentage is significantly lower than that spent in the pharmaceutical (20.5\%) and aerospace and defence (11.5\%) sectors ${ }^{10}$. Assuming the same return of 75 to $1, \$ 40$ billion would need to be invested to generate a cumulative $\$ 3$ trillion of savings. Even if only $\$ 3$ billion were invested per year until 2030 , that would still be only about $1 \%$ of the money spent on buildings-related energy.

Strategic investment offers the opportunity to reduce the US annual energy bill by hundreds of billions of dollars. Achieving an energy-efficient future is a cause that can benefit all of us.

Philip Farese is vice-president of sales support at Advantix Systems in Sunrise, Florida, the leading manufacturer of liquid-desiccant air conditioners. He was a senior energy analyst at the US National Renewable Energy Laboratory until early August 2012.

e-mail:philip.farese@advantixsystems.com

1. US Energy Information Administration Annual Energy Outlook 2012 (Department of Energy, 2012).

2. Farese, P., Gelman, R. \& Hendron, R. A Tool to Prioritize Energy Efficiency Investments (National Renewable Energy Laboratory, in the press).

3. Real Prospects for Energy Efficiency in the United States (National Academies Press, 2009).

4. Jenkins, J., Nordhaus, T. \& Shellenberger, M. Energy Emergence: Rebound \& Backfire as Emergent Phenomena (Breakthrough Institute, 2011).

5. Sorrell, S., Dimitropoulos, J. \& Sommerville, M. Energy Policy 37, 1356-1371(2009).

6. Meyers, S., Williams, A. \& Chan, P. Energy and Economic Impacts of U.S. Federal Energy and Water Conservation Standards Adopted From 1987 Through 2010 (Lawrence Berkeley National Laboratory, 2012).

7. Belzer, D. \& Cort, K. A. Projected Impacts of the Building Energy Codes Program, 2012-2030 (Pacific Northwest National Laboratory, 2012).

8. Sanchez, M., Brown, R. E., Homan, G. K. \& Webber, C. A. 2008 Status Report Savings Estimates for the ENERGY STAR Voluntary Labeling Program (Lawrence Berkeley National Laboratory, 2007).

9. National Research Council Energy Research at DOE: Was It Worth It? Energy Efficiency and Fossil Energy Research 1978 to 2000 (National Academies Press, 2001).

10. Holliday, C. et al. Catalyzing American Ingenuity (American Innovation Energy Council, 2010). 